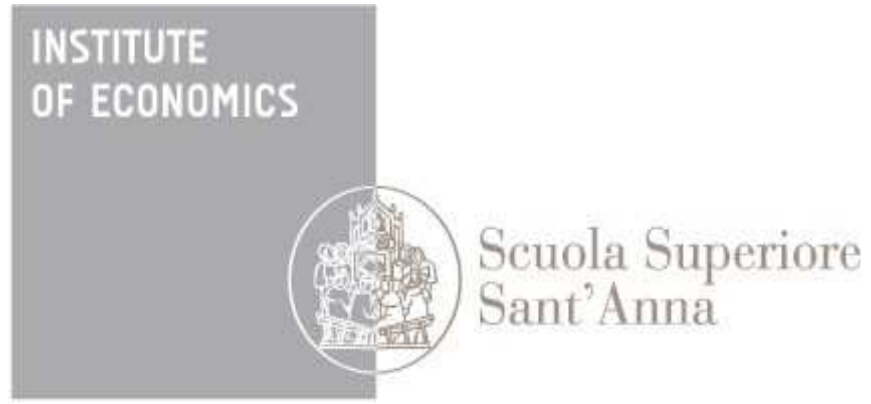

LEM | Laboratory of Economics and Management Institute of Economics

Scuola Superiore Sant'Anna

Piazza Martiri della Libertà, 33 - 56127 Pisa, Italy ph. +3905088.33 .43$

institute.economics@sssup.it

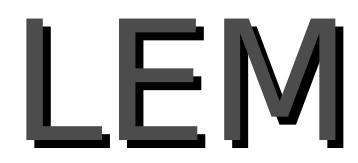

Working Paper Series

\title{
The impact of color palettes on the prices of paintings
}

\author{
Elena Stepanova ${ }^{\circ}$
}

Institute of Economics, Scuola Superiore Sant'Anna, Pisa, Italy

2017/25

October 2017

ISSN(ONLINE) 2284-0400 


\title{
The impact of color palettes on the prices of paintings
}

\author{
Elena Stepanova
}

Sant'Anna School of Advanced Studies, Pisa*

Keywords: art markets, hedonic pricing, Picasso, Rothko, visual data, color, color quantizing.

JEL Classification: Z11, C810

\begin{abstract}
We emphasize that color composition is an important characteristic of a painting. It impacts the auction price of a painting but it has never been considered in previous studies on art markets. By using Picasso's paintings and paintings of Color Field Abstract Expressionists sold in Chrisite's and Sotheby's auctions in New York between 1998 and 2016, we demonstrate the method to analyze color compositions: how to extract color palettes from a painting image and how to measure color characteristics. We propose two measures: 1) the surface occupied by specific colors, 2) color diversity of a painting composition. Controlling for all conventional painting and sale characteristics, our empirical results find significant evidence of contrastive paintings, i.e. paintings with high diversity of colors, carrying a premium than equivalent artworks which are performed in monochromatic style. In the case of Picasso's paintings, our econometric analysis shows that some colors are associated with high prices.
\end{abstract}

${ }^{*}$ The authors declare that they have no conflict of interest. Correspondence: Laboratory of Economics and Management, Sant'Anna School of Advanced Studies, 56127, Piazza Martiri della Liberta' 33, Pisa, Italy. email: e.stepanova@sssup.it. 
"Colors, like features, follow the changes of the emotions." Pablo Picasso

\section{Introduction}

As the art market bids new price records every year, the question of the main determinants of the prices of artworks returns in the focus of economics literature. Conventional price determinants can be classified into three main categories: the intrinsic characteristics of an artwork, sale conditions (country of sale, auction house and time) and acquired characteristics (provenance of an artwork, whether it was exhibited before or mentioned in art catalogues). The intrinsic characteristics of an artwork are supposed to measure its quality. Up to now the standard set of intrinsic characteristics includes size, support and the presence of the artist's signature. And there are no characteristics which measure visual appeal of an artwork. We suppose that this is caused by the inability to analyze a painting image. ${ }^{1}$ In particular, we know little about the value or premium that individuals put on color - one of the principal components of our visual perception of an artwork. This paper analyses color palettes of artworks. We propose a method to quantify color composition of an artwork. We show that color composition is an important characteristic of an artwork, and that it has an influence on a price of an artwork.

The importance of colors is confirmed in marketing literature and in psychology. There is evidence that different colors trigger different human emotions (Hemphill, 1996; Boyatzis and Varghese, 1994; Cimbalo et al., 1978). This has been extensively exploited in marketing science where researchers have found the relation between the color of products and consumer behavior (Labrecque and Milne, 2012; Puccinelli et al., 2013; Deng et al., 2010). The visual sense is the strongest sense developed in humans. Therefore it is only natural that $90 \%$ of an assessment of a product is made by color alone. This has motivated us to study whether color perception has an impact on the price of a very particular good - a painting.

Combining different colors to create more appealing color scheme is an important artifice used by artists, especially in Modern and Contemporary Art. We propose to measure the colorfulness of artworks. Some artworks are executed in polychromatic style and have few different colors while other artworks have many different colors. Intuitively, a painting with too few colors may seem to be flat while big diversity of colors makes the work more contrastive and catchy. We find higher prices for paintings with a high diversity of colors than for paintings in a monochromatic style. Additionally, on the example of one artist we show that some particular colors can be important in determining the price of an artwork. But this finding is artist-specific and we do not claim to find a universal result which is applicable to the whole art market. As each artist uses colors differently, each artist must be considered separately.

The relation between color composition of an artwork and its price is still a new research area. We did not find any previous work on it to our best knowledge. The only exception is Pownall (2014). ${ }^{2}$ Using the

\footnotetext{
${ }^{1}$ In several studies, the subject of a painting (landscape, portrait, etc.) or the number of figures [in the case of figurative works] have been considered as price explanatory variables (Etro and Pagani, 2012, 2013; Etro and Stepanova, 2015). But these studies focus on the Old Masters where the classification of subjects is unambiguous. Modern Art, in turn, presents a puzzle for defining subjects. A possible solution is to use the artist's age [under the assumption that paintings done in the same year are close in style] (Galenson, 2000; Hodgson, 2011; Hellmanzik, 2009).

${ }^{2}$ We thank our referee for pointing this out to us.
} 
example of Andy Warhol's colour-prints, she demonstrates that darker colours carry a premium. Although it is impossible to compare our results to hers due to the difference in methodologies and measures applied, we believe that the novel technique to quantify color compositions which we use in the current paper gives deeper insight into the 'color - price' relation, and that our findings complement Pownall's work. ${ }^{3}$

The paper is organized as follows. In the next section, we explain the hedonic pricing model used to measure the impact of painting characteristics on prices of paintings. In the same section, we explain our choice of the dataset and explanatory variables. We introduce the color variables, and how they are estimated from the digital images taken from electronic auction catalogues. We briefly review computer science literature on colour quantization to advocate the chosen methodology of image colour analysis. In Section 3, we discuss the results of our analysis and Section 4 provides concluding remarks.

\section{The hedonic pricing model and the data}

\subsection{The hedonic pricing model}

A vast majority of studies on price determinants have been based on a hedonic pricing model (Chanel et al., 1996; Agnello and Pierce, 1996; Higgs and Worthington, 2005) so we have adopted it as our workhorse. A hedonic price function can be used when a good has a number of elements which all add value to the price of the good. We use the hedonic function to estimate the degree to which artworks characteristics explain art prices.

The price of an artwork is regressed on a set of measurable characteristics: the intrinsic characteristics of a painting, sale characteristics, etc. The estimated regression coefficients represent the buyer's willingness to pay a premium for a particular characteristic. Here we run a hedonic regression of the (natural logarithm of) price $p_{i t}$ of work $i(i=1, \ldots, I)$ at time $t$ on the set of measurable characteristics $m(m=1, \ldots, M)$ of an artwork $i(i=1, \ldots, I)$ at time $t-x_{i m t}$ :

$$
p_{i t}=\sum_{m} \alpha_{m} x_{i m t}+c(t)+e_{i t},
$$

where $c(t)$ is the market-wide price effect. It can be represented by a time-trend or by a set of timedummies: $c(t)=\sum_{t} \gamma_{t} d_{t}$, where $d_{t}$ is a time-dummy variable of value 1 if the work is sold in period $t$, or otherwise zero.

$e_{i t}$ is an error term and $\alpha_{m}$ 's and $\gamma_{t}$ 's are parameters to be estimated in the OLS regression.

The dependent variable $-p_{i t}$ - is the (natural logarithm of) price paid by the successful bidder. ${ }^{4}$ As the dependent variable is the natural logarithm of the price, the coefficient of a particular independent variable is interpreted as the percentage change in price due to a unit change in a particular characteristic, while other characteristics are held constant. For example, if the variable canvas has a coefficient equal to $\alpha_{\text {canvas }}$, this means that the price of a painting on canvas is $\exp \left(\alpha_{\text {canvas }}\right)-1$ percent more expensive than

\footnotetext{
${ }^{3}$ Further discussion of Pownall (2014) follows in the next section.

${ }^{4}$ The price is equal to the auction hammer price plus the buyer's premium. The buyer's premia are included as these differ from period to period and, more importantly, between auction houses.
} 
the price of a painting on a wooden support - omitted from the regression to avoid linear dependency $\left(\alpha_{\text {wooden support }}=0\right.$ and $\left.\exp \left(\alpha_{\text {wooden support }}\right)=1\right)$.

Regression coefficients $\gamma_{t}$ are interpreted as the prices of the characteristic-free works of each period. They are used to construct a price index. However, if the construction of a price index is not the main research question, then the set of time-dummies, $d_{t} \mathrm{~s}$, can be replaced by a continuous time variable representing a price time trend.

\subsection{The data}

In this paper we will consider two models: one focuses on one particular artist, Picasso, and another on the group of artists belonging to Color Field Abstract Expressionism movement in art. By focusing on one particular artist, we are able to control for a large part of the heterogeneity which occurs in pricing the cross-section of artworks. But to avoid creating the impression that colour analysis is only important for the market of Picasso's works, we consider another interesting example - the school of Color Field Abstract Expressionism.

(a) Picasso

We have chosen Picasso for our econometric exercise for two reasons. Firstly, color was immensely important to Picasso. He always experimented with color palettes during his working life, and we can study whether particular colors and the ways they are combined impact prices. The second reason for our choice is that he produced an enormous number of works during his life and they are always present in the semi-annual Modern Art sales at Christie's and Sotheby's in New York. There is enough turnover in the market and market liquidity such that we have enough variation in the type of artworks and images which were sold during the time period under investigation. For this reason several cultural economists tested new methods or hypotheses on a set of Picasso's artworks (Pesando, 1993; Czujack, 1997; Scorcu and Zanola, 2011). Czujack (1997) is of special interest because the set of painting characteristics used in the paper is the largest across studies of art markets which apply the hedonic methodology. We use the same set of painting characteristics to be able to compare our results to her findings.

Our set of explanatory variables includes three major categories: sale characteristics, intrinsic characteristics of a painting and acquired painting characteristics. As our intention is to focus on intrinsic painting characteristics, we want to maintain the sample as homogenous as possible with respect to other explanatory variables. That is why we have only two major auction houses - Christie's and Sotheby's in New York to avoid price variance due to the fact that works were sold in different locations by different auction houses. At the same time, Christie's and Sotheby's in New York are principal marketplaces for Picasso's works (they have the largest market share of his sold works in the world).

Sale characteristics are the following: 1) the year of sale (we take the time frame: 1998 - 2016); 2) the auction house and 3) the evening auction dummy (sales of important artworks take place in the evening and, indeed, the average price of an item from an evening auction is eight times higher than the average price of an item from a day auction in our sample).

Acquired characteristics represent the history of a particular painting and include 1) how many times the work was publicly exhibited and 2) how many different artbooks mentioned it (we define a variable 
'mentioned in more than 2 artbooks'). ${ }^{5}$ This information is provided in auction catalogues.

The intrinsic characteristics of a painting include: 1) canvas or wooden support (we have selected only oil paintings executed on a canvas or wooden support in order to have a homogeneous sample; this leaves out Picasso's works on paper, collages and mixed techniques ${ }^{6}$ ); 2) size; 3) signature and date; 4) to proxy the painting genre we have attributed his paintings to eight major working periods (as defined in Czujack, 1997). The eight periods differ according to quality, number of paintings produced and their genres. The 127 sold items in our sample (37 \%) belong to the last and longest period - the Old Picasso period which lasted from 1954 to 1973 in which Picasso produced many paintings that were not new conceptually and the themes repeated each other. The highest prices are associated with the Blue and Rose Period (1902 1906) and we have 7 items from this period in our dataset. This period lasted 4 years and it is associated with the first paintings in Picasso's style. In an alternative regression, we use a continuous variable, the artist's age, instead of working periods.

The list of the intrinsic characteristics of a painting also includes color variables which we will define in the next section after explaining how we quantify color.

Summary statistics for all explanatory variables are given in Appendix Table 3.

\section{(b) Color Field Abstract Expressionism}

The works of artists who belong to Color Field Abstract Expressionism are freed from the subjective and objective contexts. Color composition is the only subject. The Color Field painters sought to rid their art of superfluous rhetoric. Their works present abstraction as an end in itself. Any recognizable imagery is eliminated. Only flat areas of color are present, which these artists considered to be the essential nature of visual abstraction (Anfam, 1990; Sandler, 1976; Landau, 2005). Very influential artists, Adolph Gottlieb, Robert Motherwell, Clyfford Still, Hans Hofmann and Mark Rothko, are classical representatives of this art direction, and this is without mentioning the sensational prices that their works have recently obtained. We have a sample of 371 observations of their paintings sold at NY Christie's and Sotheby's in the period 1998 - 2016. For each observation, we have information on size, signature, type of support and date of creation (summary statistics of variables is given in Appendix Table 4). This art direction represents an interesting case for testing our hypothesis that color composition influences painting price.

\footnotetext{
${ }^{5}$ In the period 1942 to 1978, Christian Zervos produced 34 volumes of catalogue raisonnee, in which most of Picasso's works are registered. This registration is considered to be a proof of authenticity and it is assumed to influence prices. In our case, Christie's and Sotheby's only auction authentic works and in the Provenance indicate, apart from Christian Zervos catalogue raisonnee, other important art catalogues. So the variable 'mentioned in more than 2 art books' means that the painting is mentioned not only in Christian Zervos catalogue raisonnee but in some other art catalogues. Pre-auction catalogue information refers to extremely prominent and influential publications. It is reasonable to expect that Christie's and Sotheby's use valuable catalogue space to report the fact that the piece has been reproduced in a book only if it is perceived as an important work of reference. We expect such references to have a positive effect on prices.

${ }^{6}$ Works on paper and collages are usually drafts of his oil paintings with prevailing use of black and white colors to sketch the objects, so we don't want to consider these works in our analyses of Picasso's color palette
} 


\subsection{Quantifying color}

For each observation, we have a digital image of a painting. We obtained the image from the auction catalogues that are available on the websites of the auction houses. ${ }^{7}$ We believe that this is a precious source of information but it has been disregarded in the economic analysis of art market prices.

Digital images are represented by pixels. Each pixel has a colour which is a coordinate in the threedimensional integer R-G-B space (Red-Green-Blue). The R-G-B space is the conventional way to represent colour in electronic systems, computers, cameras, etc. and it is grounded on the theory of the human perception of colors. The RGB scale goes from 0 to 250 where R 0 G 0 B 0 is pure black and R 250 G 250 B 250 is pure white. It distinguishes between 15.6 million $\left(250^{3}\right)$ different colors.

In our sample, an image contains 2000 different RGB colors on average but most of them are just brightness and gradient variations of the principal colors. We are faced with the classical statistical problem of dimensionality reduction, where for each observation [each image] we want to reduce the number of RGB colours to the principal ones i.e., those that occupy the most space on the image.

Facing the same problem of dimensionality reduction, Pownall (2014) calculates average values of red$\mathrm{R}$, green- $\mathrm{G}$ and blue-B for each observation [each image]. These average values are significant in her hedonic regression models. But each of her regressions includes only one variable: or average value of red$\mathrm{R}$, or average value of green-G, or average value of blue- $\mathrm{B}$. There is no regression where all three variables appear together, so we don't know how their mutual behavior impacts the price. The significance of the average values allows to conclude that color is an important painting characteristics, and that darker colours, i.e. smaller values of average red-R (green-G or blue-B), carry a premium. This is very simple solution to the problem of dimensionality reduction. But as nothing is mentioned about mutual behavior of the color variables it is hard to give visual interpretation of the result: Does the finding mean that absolutely black painting - R 0 G 0 B 0 will have the highest price?

Figure 1: Quantizing colors

FEMME ASSISE DANS UN FAUTEUIL, Sotheby's 2 May 2012,

Price 29202500 USD

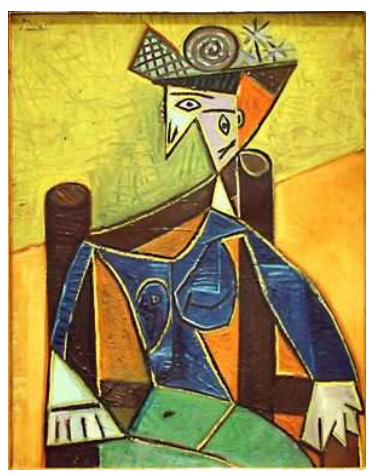

The RGB color code and the percentage of space occupied on the image

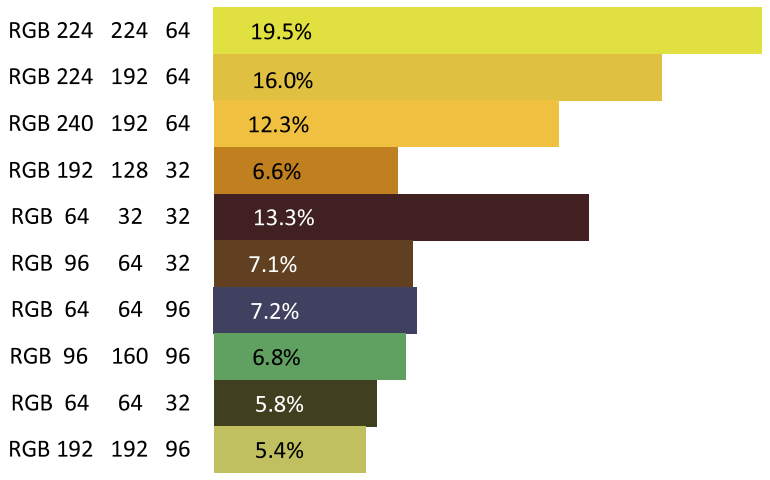

\footnotetext{
${ }^{7}$ In a small number of cases, auction catalogues on websites are not available for free. Alternative solutions are the online databases artvalue.com and artsalesindex.artinfo.com
} 
The interpretation of the results impedes us from employing principal components analysis frequently used for the dimensionality reduction problems. Instead, we use clustering approach which allows us to construct explanatory variables with nice visual interpretation. The three-dimensional clustering algorithm is applied (also known in computer science as color quantizing algorithm, Orchard et al. (1991); Brun and Trémeau (2003)). It rounds up the colors that are close to each other in the sense of the Euclidian distance in the RGB space. For each image, we identify 10 principal colors that occupy the most space and the percentage of space occupied by each color (an example is provided in Figure 1). ${ }^{8}$ Color clustering is the main technique used in computer science for image data compression, that is, the reduction of the amount of data (number of pixels) needed to display an image while preserving the main color characteristics so that the human eye cannot see the number of colors reduced (Orchard et al., 1991; Brun and Trémeau, 2003). The same principles are used 1) in image search-engines, where only the main color characteristics of an image are needed to identify whether an image corresponds to the search query (Niblack et al., 1993); 2) in robot vision - to identify objects by their color characteristics (Swain and Ballard, 1991).

We propose two approaches to characterize the color composition of a painting: a) presence of specific colors b) color diversity.

\section{(a) Color clusters}

A possible approach to quantify the impact of color on a price of an artwork is the identification of colors which carry a premium if they are present on an artwork. But this approach is artist-specific. We demonstrate it on Picasso's artworks and we do not claim to find a universal result which is applicable to the whole art market.

Figure 2a displays all of the 200 principal colors that were found on Picasso's paintings weighted by how many times we encountered each color. Figure $2 \mathrm{~b}$, in turn, displays the same colors but weighted by the average price of the paintings on which we found the color. From Figure 2a, we notice that colors from the main diagonal [which connects full black with full white and goes through all variations of gray] - black/gray spectrum, and colors close to the black/gray spectrum (ochres, cream and brown) are frequently used and we find them on a large number of works. But the main diagonal loses all its weight in Figure 2b. The weight, in terms of average prices, moves to colors that are distant from the main diagonal.

In Figure 2b, one can see two concentration areas: the blue-teal colors and the orange colors. We identify these two concentration areas by specifying two spheres centered in the most "heavy" [in price terms] points and with a radius big enough to cover the concentration area of high priced colors (Figure $2 \mathrm{~b}$ ). We call them the blue-teal cluster and the orange cluster. The blue-teal cluster is centered in R 32 G 128 B 128 and it has a radius of 72 points. The orange cluster is centered in R 192 G 128 B 32 and it has a radius of 45 points.

\footnotetext{
${ }^{8} \mathrm{As}$ color brightness and gradients are rounded off, it is not critical that there may be differences in the brightness of an image due to the amount of external light hitting the object. We also do not need high image resolution, i.e. a larger amount of pixels (a color is associated with each pixel), because we round off colors to the principal ones. Actually, the color quantizing algorithm is a workhorse tool in computer science used to reduce the memory weight of an image (image resolution) while preserving its color characteristics.
} 
Figure 2: Distribution of colors encountered on the paintings of Picasso

(a) weighted by the encounter frequency

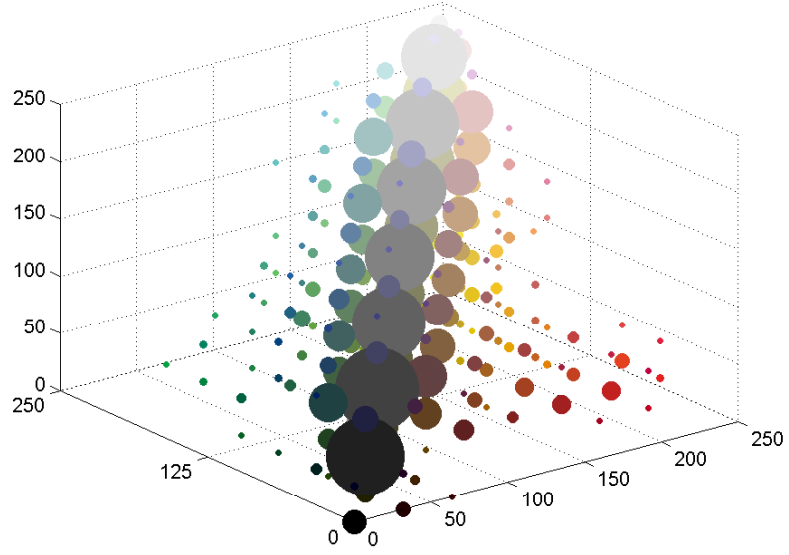

(b) weighted by the average price of works on which we encounter the color; with 2 clusters of high priced colors

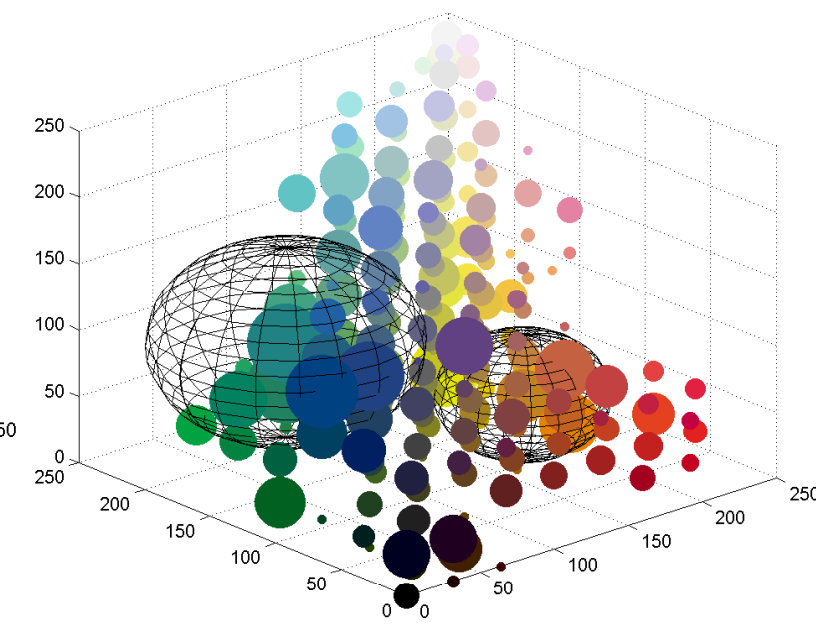

116 paintings from our dataset (or $40 \%$ of the dataset) have colors from the blue-teal cluster (see Figure 5 for examples of these paintings), and, on average, these colors cover $14 \%$ of the surface of the paintings and the average price for them is $7 \mathrm{mln}$. USD (this is $30 \%$ higher than the average price of a painting in our dataset). 38 paintings from our dataset (or $12 \%$ of the dataset) have colors from the orange cluster (see Figure 6 for examples of these paintings), and, on average, these colors cover $12 \%$ of the surface of the paintings and the average price for them is $8 \mathrm{mln}$. USD (this is $48 \%$ higher than the average price of a painting in our dataset). We introduce two variables for these two clusters - the surface of a painting occupied by colors from the given cluster.

\section{(b) Color diversity of a painting composition}

For each painting, we define the diversity of colors as an average euclidean distance in the RGB space between the colors that are on the painting. We suppose that the bigger the diversity of colors is, the more catchy and more contrastive is the painting. We expect higher prices for paintings with a high diversity of colors than for paintings in a monochromatic style. A painting composed of pure blue (R 0 G 0 B 250) and yellow (R 250 G 250 B 0), colors that are the most distant from each other on the RGB space, will have the highest color diversity. Figure 4 presents the distribution of color diversity for Picasso paintings and for Color Field Abstract Expressionists. We see left-skewed distribution in the case of Color Field Abstract Expressionists. This can be explained by the presence of many monochromatic works (one of them is presented on Figure 3): two, three colors similar to each other occupy all space of a painting.

Figure 3 gives examples of paintings: with high and low color diversity. 
Figure 3: Diversity of the painting colors

Pablo Picasso

\section{Low diversity}

average distance between colors

is 53 points in the RGB space

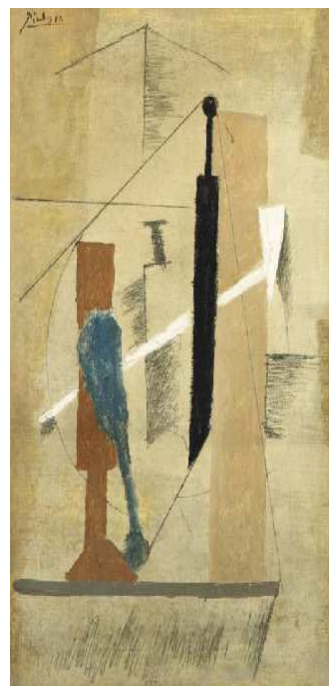

Bouteille, verre et pipe, 1914

Christie's 10 Nov 1999

Price 167500 USD

\section{High diversity}

average distance between colors is 165 points in the RGB space

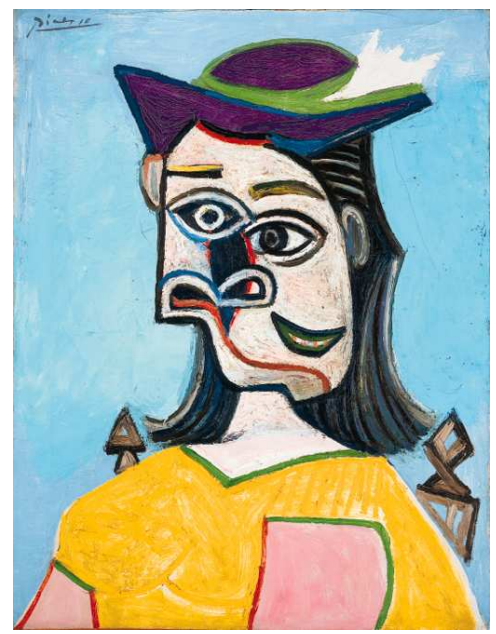

Buste de femme assise sur une chaise, 1939

Christie's 9 May 2000

Price 4736000 USD

Mark Rothko

\section{High diversity}

average distance between colors is 175 points in the RGB space

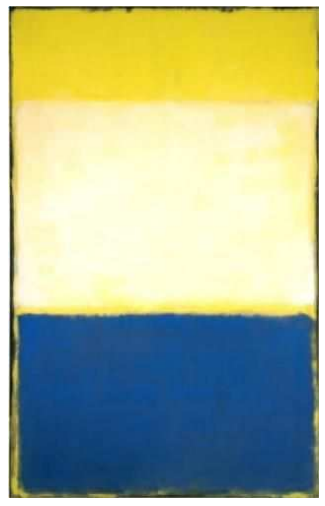

NO.6(Yellow, White, Blue over

Yellow on Gray), 1954

Sotheby's 9 Nov 2004

Price 17368000 USD

Sotheby's 14 Nov 2007

Price 7881000 USD 


\section{Empirical results}

The results of our hedonic pricing models are discussed in this section. First, we discuss the general results of hedonic models and then we study how the differences in art prices across paintings are influenced by color.

We start by verifying results commonly seen in the literature. In particular, we refer to the study of Czujack (1997). Although, her sample is heterogeneous in geographical locations, auction houses, types of artworks (collages and works on paper are considered together with oil paintings) and the time span is twice as long as ours (1963 - 1994), we can compare results for several explanatory variables: size, signature and - most importantly - the working periods. Table 1 shows the empirical results for four regressions: 1) and 2) are regressions on a full data sample, they differ by color variables included; 2) regression with observations from the "Blue and Red Period" being excluded from the sample; 3) reduced form regression when working periods are replaced by a continuous variable, the artist's age, and time-period dummies

are replaced by a continuous variable, year of sale. All regressions deliver similar results. All versions have a high $70 \% \mathrm{R}^{2}$.

We find price difference between a canvas and a wooden support in line with (Czujack, 1997). A canvas is on average $28 \%(\exp (0.25)-1)$ more expensive than a wooden support. Also in line with her findings, we do not observe that the artist's signature has a significant influence on prices. Fame has a positive impact on price and a painting that is mentioned in several art books has, on average, a $60 \%$ higher sale price $(\exp (0.47)-1)$. We observe significant price differences between sales in Christie's and Sotheby's auctions in line with Pesando (1993) and Pesando and Shum (1996) who find significant price differences between Christie's and Sotheby's auctions in New York in the case of Picasso's prints. This is a puzzle because these results don't confirm the "law of one price" which states that, in the absence of different transaction costs, no systematic price differences should exist between distinct market places for the same good (Ashenfelter and Graddy, 2003). We confirm the presence of the afternoon effect (Beggs and Graddy, 1997) with expensive works being sold in the evening sessions. Prices are positively correlated with the size of the paintings. There is a nonlinear increase in price with an increase in the size of the painting as captured by the negative and significant coefficient of the squared size of the work. In other words, evidence shows the expected results of a typical hedonic regression.

Using the time dummies, we built a bi-annual price index for the market of Picasso's works (Figure 8) which indicates a strong increase. Indeed, reduced form regression (Table 1, column 4) shows that the annual price increase is on average $6.7 \%$.

By examining Picasso's working periods, we confirm Czujack (1997) finding that the most expensive period is the "Blue and Red Picasso" and the cheapest one is the "Old Picasso". She finds that the second highest prices are obtained by works from the "Cubism Period", while we find that the second highest prices are associated with the "Guermica and the Style Picasso" - Symbolism that made him famous all over the world. The age-price profile of Picasso (Figure 7) is referred in Galenson (2011) as a canonical example of conceptual innovator or young genius who make radical innovations in the field at a very early age. 
Table 1: Picasso's paintings at auctions - Regression results

\begin{tabular}{|c|c|c|c|c|c|c|c|c|}
\hline Dependent variable: $\log$ Price & \multicolumn{2}{|c|}{ Full sample } & \multicolumn{2}{|c|}{ Full sample } & \multicolumn{2}{|c|}{$\begin{array}{c}\text { Excluded } \\
\text { Blue and Red Period" }\end{array}$} & \multicolumn{2}{|c|}{$\begin{array}{l}\text { Reduced form } \\
\text { regression }\end{array}$} \\
\hline Time dummies (see Figure 8) & \multicolumn{2}{|c|}{ YES } & \multicolumn{2}{|c|}{ YES } & \multicolumn{2}{|c|}{ YES } & \multicolumn{2}{|c|}{-} \\
\hline Year of sale & & & & & & & $0.067^{* * *}$ & $(0.009)$ \\
\hline \multicolumn{9}{|l|}{$\log$ Diversity of colors } \\
\hline (point-distance in RGB space) & & & $0.579^{* * *}$ & $(0.171)$ & $0.585^{* * *}$ & $(0.164)$ & $0.568^{* * *}$ & $(0.165)$ \\
\hline \multicolumn{9}{|l|}{ Surface occupied by colors } \\
\hline in the blue-teal cluster (in $1000 \mathrm{~cm}^{2}$ ) & $0.210^{* * *}$ & $(0.066)$ & $0.195^{* * *}$ & $(0.064)$ & $0.140^{* *}$ & $(0.063)$ & $0.247^{* * *}$ & $(0.066)$ \\
\hline \multicolumn{9}{|l|}{ Surface occupied by colors } \\
\hline in the orange cluster (in $1000 \mathrm{~cm}^{2}$ ) & $0.360^{* *}$ & $(0.145)$ & $0.345^{* *}$ & $(0.142)$ & $0.342^{* *}$ & $(0.136)$ & $0.450^{* * *}$ & $(0.144)$ \\
\hline Surface (in $1000 \mathrm{~cm}^{2}$ ) & $0.141^{* * *}$ & $(0.026)$ & $0.154^{* * *}$ & $(0.026)$ & $0.168^{* * *}$ & $(0.025)$ & $0.136^{* * *}$ & $(0.026)$ \\
\hline Surface squared & $-0.003^{* * *}$ & $(0.001)$ & $-0.004^{* * *}$ & $(0.001)$ & $-0.004^{* * *}$ & $(0.001)$ & $-0.004^{* * *}$ & $(0.001)$ \\
\hline Canvas vs wooden support & $0.254^{* *}$ & $(0.129)$ & $0.245^{*}$ & $(0.127)$ & $0.263^{* *}$ & $(0.123)$ & $0.258^{* *}$ & $(0.127)$ \\
\hline Signed & 0.092 & $(0.099)$ & 0.076 & $(0.097)$ & 0.016 & $(0.094)$ & 0.070 & $(0.100)$ \\
\hline Dated & 0.073 & $(0.138)$ & 0.040 & $(0.135)$ & 0.041 & $(0.129)$ & 0.072 & $(0.136)$ \\
\hline Mentioned in more than 2 artbooks & $0.475^{* * *}$ & $(0.105)$ & $0.434^{* * *}$ & $(0.103)$ & $0.397^{* * *}$ & $(0.099)$ & $0.429^{* * *}$ & $(0.101)$ \\
\hline Exhibited & 0.021 & $(0.015)$ & 0.019 & $(0.015)$ & 0.020 & $(0.014)$ & $0.028^{*}$ & $(0.015)$ \\
\hline Evening sale & $1.013^{* * *}$ & $(0.122)$ & $0.974^{* * *}$ & $(0.120)$ & $0.947^{* * *}$ & $(0.116)$ & $1.089^{* * *}$ & $(0.119)$ \\
\hline Sotheby's vs Christie's & $0.200^{* *}$ & $(0.102)$ & 0.153 & $(0.101)$ & 0.116 & $(0.097)$ & $0.184^{*}$ & $(0.101)$ \\
\hline Artist's age & & & & & & & $-0.007^{* *}$ & $(0.003)$ \\
\hline \multicolumn{9}{|l|}{ Working periods (see Figure 7) } \\
\hline (1881-1901) Child and Youth & \multicolumn{2}{|c|}{ omitted } & \multicolumn{2}{|c|}{ omitted } & \multicolumn{2}{|c|}{ omitted } & & \\
\hline (1902-1906) Blue and Rose Period & 0.484 & $(0.331)$ & $0.642^{*}$ & $(0.328)$ & & - & & \\
\hline (1907-1915) Analytical and Synthetic Cubism & -0.207 & $(0.271)$ & -0.122 & $(0.267)$ & -0.158 & $(0.254)$ & & \\
\hline (1916-1924) Camera and Classicism & -0.269 & $(0.238)$ & -0.349 & $(0.235)$ & $-0.426^{*}$ & $(0.225)$ & & \\
\hline (1925-1936) Juggler of the Form & 0.078 & $(0.238)$ & -0.062 & $(0.237)$ & -0.128 & $(0.226)$ & & \\
\hline (1937-1943) Guernica and the "Style Picasso" & 0.313 & $(0.251)$ & 0.162 & $(0.250)$ & 0.090 & $(0.239)$ & & \\
\hline (1944-1953) Politics and Art & -0.128 & $(0.269)$ & -0.272 & $(0.267)$ & -0.349 & $(0.256)$ & & \\
\hline (1954-1973) The Old Picasso & -0.277 & $(0.262)$ & $-0.448^{*}$ & $(0.262)$ & $-0.544^{* *}$ & $(0.251)$ & & \\
\hline Constant & $12.028^{* * *}$ & $(0.279)$ & $12.647^{* * *}$ & $(0.329)$ & $12.749^{* * *}$ & $(0.316)$ & $-107.305^{* * *}$ & $(19.535)$ \\
\hline Observations & 296 & & 296 & & 289 & & 296 & \\
\hline Variables & 27 & & 28 & & 27 & & 14 & \\
\hline $\mathrm{R}^{2}$ & 0.704 & & 0.716 & & 0.737 & & 0.671 & \\
\hline
\end{tabular}




\section{(a) Color clusters}

Our main finding is the existence of a strong positive correlation between the price of a work and its surface occupied by colors from the blue-teal and orange clusters. A $1000 \mathrm{~cm}^{2}$ increase of surface painted in blue-teal colors (which is $15 \%$ of the average size of a painting in our dataset) gives a $23 \%(\exp (0.21)-1)$ increase in the sale price. The same holds for orange colors which give a $43 \%$ increase. One can suppose that the presence of colors from the blue-teal cluster on a painting is correlated with the painting being produced during Picasso's Blue Period - the most expensive one. However, the correlation is only 7\% and, as shown on Figure 7, Picasso was using blue in all his working periods. Additionally, as shown on Figure 5, the "blue" painting from 1953 (i.e. from Picasso's Politics and Art period) was sold at twice the price than the average price in our sample. We confirm our results even after the exclusion of observations from the Blue Period from the regression (Table 1, column 3).

\section{(b) Color diversity of a painting composition}

The presence of contrastive colors on the same painting is strongly and positively correlated with price. We log-transformed the explanatory variable so the result should be interpreted as follows: a $1 \%$ increase of the average distance between colors of the same painting increases the price by $58 \%$ (the second column of Table 1). Table 2 presents the regression for the group of artists - Color Field Abstract Expressionists. We confirm our finding that the higher is the diversity of colors on an artwork, the higher is its price. Table 2 also contains the reduced form regression for Picasso. So we can confront the magnitude of the regression coefficient for the color diversity. We see that the value of the coefficient is higher in the case of Picasso than in the case of the Color Field.

Table 2: Diversity of colors - Regression results

\begin{tabular}{|c|c|c|c|c|}
\hline Dependent variable: $\log$ Price & \multicolumn{2}{|r|}{ Picasso } & \multicolumn{2}{|c|}{$\begin{array}{c}\text { Color Field } \\
\text { Abstract Expressionism }\end{array}$} \\
\hline Time dummies (see Figure 8) & & YES & & $\mathrm{ES}$ \\
\hline Artists dummies & & - & & $\mathrm{ES}$ \\
\hline $\log$ Diversity of colors (point-distance in RGB space) & $0.711^{* * *}$ & $(0.177)$ & $0.435^{* * *}$ & $(0.155)$ \\
\hline Surface (in $1000 \mathrm{~cm}^{2}$ ) & $0.196^{* * *}$ & $(0.025)$ & $0.081^{* * *}$ & $(0.006)$ \\
\hline Surface squared & $-0.005^{* * *}$ & $(0.001)$ & $-0.001^{* * *}$ & $(0.00005)$ \\
\hline Canvas vs wooden support & $0.218^{*}$ & $(0.129)$ & $0.485^{* * *}$ & $(0.140)$ \\
\hline Signed & 0.044 & $(0.104)$ & 0.221 & $(0.144)$ \\
\hline Sotheby's vs Christie's & 0.098 & $(0.107)$ & -0.043 & $(0.105)$ \\
\hline Artist's age & $-0.012^{* * *}$ & $(0.003)$ & $0.021^{* * *}$ & $(0.005)$ \\
\hline Constant & $35.259^{* * *}$ & $(5.304)$ & $-32.037^{* * *}$ & $(10.499)$ \\
\hline Observations & 296 & & 371 & \\
\hline Variables & 16 & & 20 & \\
\hline $\mathrm{R}^{2}$ & 0.649 & & 0.774 & \\
\hline
\end{tabular}




\section{Conclusion}

The paper builds a connection between human aesthetic assessment of artworks reflected, at least in part, in prices and visual characteristics of artworks - color palettes, which we are able to extract thanks to computational advances in image processing. The framework proposed in the paper can be a useful tool for art experts, art appraisers and art collectors interested in precise valuations of artworks. Our work is not meant to provide full answers, but rather to inspire more interest in this new and amazing research direction. In the examples of Picasso's works and the works of the Color Field Expressionists, we show that the analysis of color palettes is a fruitful research direction towards explaining the price variation of artworks. It is especially important for Modern Art where intrinsic painting characteristics, that can be used to explain price variation, are limited. In turn, the role of color in Modern Art is conceptual. That is why color analysis is an essential part of a hedonic pricing model for the market of a particular artist or a particular art direction in Modern and Contemporary Art. We show that, in the case of Picasso, the premium is paid for paintings with contrastive colors and with blue-teal and orange colors. In the case of Color Field Expressionism, the premium is paid for works with contrastive colors.

Apart from Modern Art, there is another application for color analysis in the primary market for paintings of the Renaissance and Baroque periods. In those times, the production of some pigments was

expensive then and the colors used to execute an artwork were an important price component. Therefore, our method will be of use in the studies of historical markets for paintings as well.

\section{References}

Agnello, R. J. and R. K. Pierce (1996). Financial returns, price determinants, and genre effects in American art investment. Journal of Cultural Economics 20(4), 359-383.

Anfam, D. (1990). Abstract Expressionism (World of Art). Thames \& Hudson.

Ashenfelter, O. and K. Graddy (2003). Auctions and the price of art. Journal of Economic Literature $41(3), 763-787$.

Beggs, A. and K. Graddy (1997). Declining values and the afternoon effect: Evidence from art auctions. The Rand journal of economics, 544-565.

Boyatzis, C. J. and R. Varghese (1994). Children's emotional associations with colors. The Journal of genetic psychology 155(1), 77-85.

Brun, L. and A. Trémeau (2003). Color quantization. In G. Sharma (Ed.), Digital color imaging handbook, pp. 589-638. Boca Raton, FL : CRC Press.

Chanel, O., L.-A. Gérard-Varet, and V. Ginsburgh (1996). The relevance of hedonic price indices. Journal of Cultural Economics 20(1), 1-24.

Cimbalo, R. S., K. L. Beck, and D. S. Sendziak (1978). Emotionally toned pictures and color selection for children and college students. The Journal of Genetic Psychology 133(2), 303-304.

Czujack, C. (1997). Picasso paintings at auction, 1963-1994. Journal of Cultural Economics 21(3), $229-247$. 
Deng, X., S. K. Hui, and J. W. Hutchinson (2010). Consumer preferences for color combinations: An empirical analysis of similarity-based color relationships. Journal of Consumer Psychology 20(4), 476484.

Etro, F. and L. Pagani (2012). The market for paintings in italy during the seventeenth century. The Journal of Economic History 72(02), 423-447.

Etro, F. and L. Pagani (2013). The market for paintings in the venetian republic from renaissance to rococò. Journal of Cultural Economics 37(4), 391-415.

Etro, F. and E. Stepanova (2015). The market for paintings in paris between rococo and romanticism. Kyklos 68(1), 28-50.

Galenson, D. W. (2000). The careers of modern artists. Journal of Cultural Economics 24(2), 87-112.

Galenson, D. W. (2011). Old masters and young geniuses: The two life cycles of artistic creativity. Princeton University Press.

Hellmanzik, C. (2009). Artistic styles: revisiting the analysis of modern artists careers. Journal of Cultural Economics 33(3), 201-232.

Hemphill, M. (1996). A note on adults' color-emotion associations. The Journal of genetic psychology $157(3), 275-280$.

Higgs, H. and A. Worthington (2005). Financial returns and price determinants in the australian art market, 1973-2003. Economic record 81(253), 113-123.

Hodgson, D. J. (2011). Age-price profiles for canadian painters at auction. Journal of Cultural Economics 35(4), 287.

Labrecque, L. I. and G. R. Milne (2012). Exciting red and competent blue: the importance of color in marketing. Journal of the Academy of Marketing Science 40(5), 711-727.

Landau, E. G. (2005). Reading Abstract Expressionism: Context and Critique. Yale University Press.

Niblack, C. W., R. Barber, W. Equitz, M. D. Flickner, E. H. Glasman, D. Petkovic, P. Yanker, C. Faloutsos, and G. Taubin (1993). Ibm research project: Qbic project - querying images by content, using color, texture, and shape. In ISET/SPIE's Symposium on Electronic Imaging: Science and Technology, pp. 173-187. International Society for Optics and Photonics.

Orchard, M. T., C. Bouman, et al. (1991). Color quantization of images. Signal Processing, IEEE Transactions on 39(12), 2677-2690.

Pesando, J. and P. M. Shum (1996). Price anomalies at auction: Evidence from the market for modern prints. In V. Ginsburgh (Ed.), Economics of the Arts: Selected Essays, pp. 113-134. Elservier, Amsterdam.

Pesando, J. E. (1993). Art as an investment: The market for modern prints. The American Economic Review, 1075-1089.

Pownall, R. A. J. (2014). Pricing colour intensity in contemporary art. Proceedings of the International Conference of The Association for Cultural Economics.

Puccinelli, N. M., R. Chandrashekaran, D. Grewal, and R. Suri (2013). Are men seduced by red? the effect of red versus black prices on price perceptions. Journal of Retailing 89(2), 115-125.

Sandler, I. (1976). The Triumph of American Painting: A History of Abstract Expressionism. Harper \& Row. 
Scorcu, A. E. and R. Zanola (2011). The right price for art collectibles: A quantile hedonic regression investigation of picasso paintings. The Journal of Alternative Investments 14 (2), 89-99.

Swain, M. J. and D. H. Ballard (1991). Color indexing. International journal of computer vision 7(1), $11-32$.

Table 3: Descriptive statistics (Picasso's paintings sold in New York in 1998-2016)

\begin{tabular}{|c|c|c|c|c|c|}
\hline & Mean & St.Dev & Min & Max & $\begin{array}{r}\text { Av.price } \\
\text { (USD) }\end{array}$ \\
\hline Price (in USD) & 5704449 & 8382733 & 101500 & 67450000 & \\
\hline $\begin{array}{l}\text { Diversity of painting colors } \\
\text { (average distance between colors in RGB space) }\end{array}$ & 105.4 & 28.43 & 50.5 & 184.5 & \\
\hline $\begin{array}{l}\text { Surface occupied by colors in blue-teal } \\
\text { cluster (in } 1000 \mathrm{~cm}^{2} \text { ) }\end{array}$ & 0.26 & 0.7 & 0 & 5.8 & \\
\hline $\begin{array}{l}\text { Surface occupied by colors in orange } \\
\text { cluster (in } 1000 \mathrm{~cm}^{2} \text { ) }\end{array}$ & 0.07 & 0.35 & 0 & 3.7 & \\
\hline Surface (in $1000 \mathrm{~cm}^{2}$ ) & 6.00 & 6.12 & 0.25 & 26.68 & \\
\hline Canvas & 0.85 & 0.36 & 0 & 1 & 6040644 \\
\hline Wooden support & 0.15 & 0.36 & 0 & 1 & 3980460 \\
\hline Signed & 0.74 & 0.44 & 0 & 1 & 5809454 \\
\hline Dated & 0.68 & 0.47 & 0 & 1 & 5593500 \\
\hline Mentioned in $0-2$ art-books & 0.54 & 0.5 & 0 & 1 & 2690265 \\
\hline Mentioned in $>2$ art-books & 0.46 & 0.5 & 0 & 1 & 8843358 \\
\hline Exhibited & 2.32 & 3.31 & 0 & 20 & \\
\hline Evening sale & 0.78 & 0.41 & 0 & 1 & 7095347 \\
\hline Day sale & 0.22 & 0.41 & 0 & 1 & 857380 \\
\hline Sotheby's & 0.37 & 0.48 & 0 & 1 & 7439886 \\
\hline Christie's & 0.63 & 0.48 & 0 & 1 & 4805582 \\
\hline \multicolumn{6}{|l|}{ Working periods } \\
\hline Child and Youth (1881-1901) & 0.06 & 0.23 & 0 & 1 & 6531605 \\
\hline Blue and Rose period (1902-1906) & 0.02 & 0.16 & 0 & 1 & 14094071 \\
\hline Analytical and Synthetic Cubism (1907-1915) & 0.05 & 0.2 & 0 & 1 & 3187738 \\
\hline Camera and Classicism (1916-1924) & 0.12 & 0.33 & 0 & 1 & 2743730 \\
\hline Juggler of the Form (1925-1936) & 0.14 & 0.36 & 0 & 1 & 8119268 \\
\hline Guernica and the "Style Picasso" (1937-1943) & 0.11 & 0.31 & 0 & 1 & 7945514 \\
\hline Politics and Art (1944-1953) & 0.12 & 0.32 & 0 & 1 & 4006710 \\
\hline The Old Picasso (1954-1973) & 0.37 & 0.49 & 0 & 1 & 5197254 \\
\hline
\end{tabular}


Table 4: Descriptive statistics (Color Field Abstract Expressionists paintings sold in New York in 19982016)

\begin{tabular}{|c|c|c|c|c|c|}
\hline & Mean & St.Dev & Min & Max & $\begin{array}{r}\text { Av.price } \\
\text { (USD) }\end{array}$ \\
\hline Price (in USD) & 5704449 & 8382733 & 101500 & 67450000 & \\
\hline $\begin{array}{l}\text { Diversity of painting colors } \\
\text { (average distance between colors in RGB space) }\end{array}$ & 92.8 & 28.43 & 24.1 & 186.7 & \\
\hline \multicolumn{6}{|l|}{ Artists } \\
\hline Adolph Gottlieb (1903-1974) & 0.06 & 0.24 & 0 & 1 & 1024315 \\
\hline Hans Hofmann (1880-1966) & 0.37 & 0.48 & 0 & 1 & 607604 \\
\hline Robert Motherwell (1915-1991) & 0.25 & 0.43 & 0 & 1 & 572450 \\
\hline Mark Rothko (1903-1970) & 0.26 & 0.44 & 0 & 1 & 13473714 \\
\hline Clyfford Still (1904-1980) & 0.05 & 0.23 & 0 & 1 & 14166000 \\
\hline Surface (in $1000 \mathrm{~cm}^{2}$ ) & 17.00 & 20.15 & 0.21 & 177.75 & \\
\hline Canvas & 0.67 & 0.47 & 0 & 1 & 6708166 \\
\hline Wooden support & 0.33 & 0.47 & 0 & 1 & 560223 \\
\hline Signed & 0.80 & 0.40 & 0 & 1 & 5809454 \\
\hline Sotheby's & 0.47 & 0.50 & 0 & 1 & 4330850 \\
\hline Christie's & 0.53 & 0.50 & 0 & 1 & 5021202 \\
\hline
\end{tabular}

Figure 4: Distribution of the diversity of the painting colors (Picasso and Color Field Abstract Expressionists artworks)

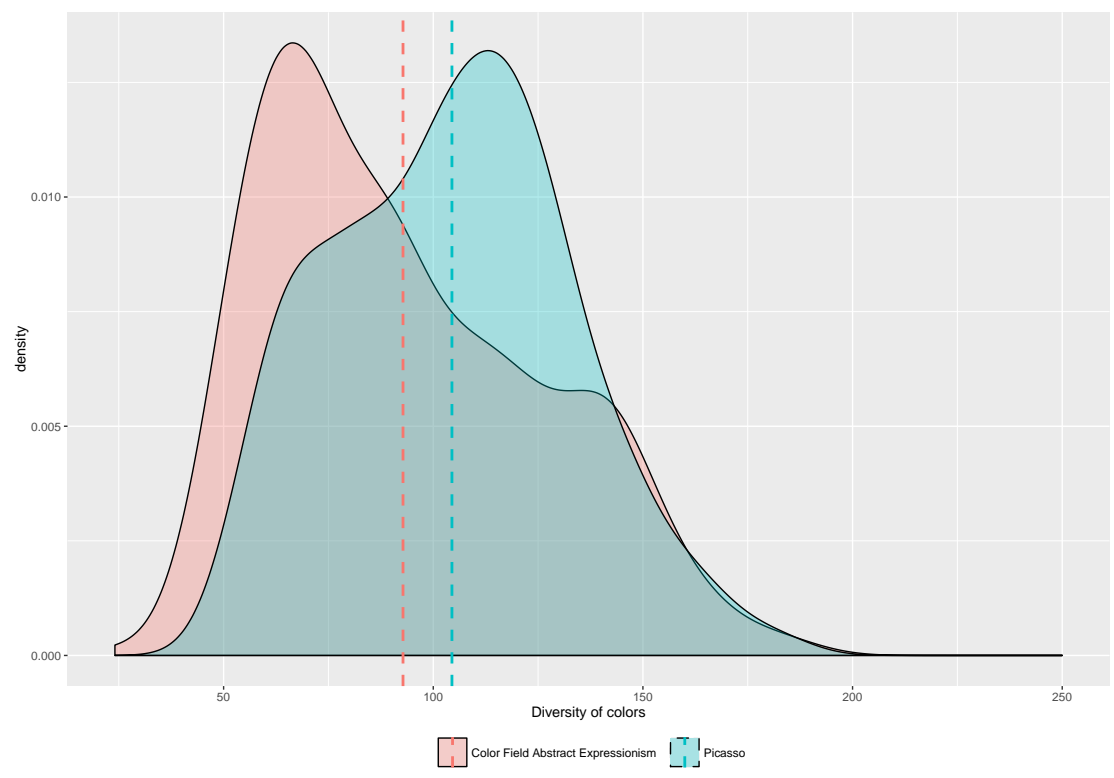


Figure 5: Example of paintings that belong to the blue-teal cluster

FEMME AUX BRAS

CROISES, 1902

Christie's 8 Nov 2000

Price 55006000 USD

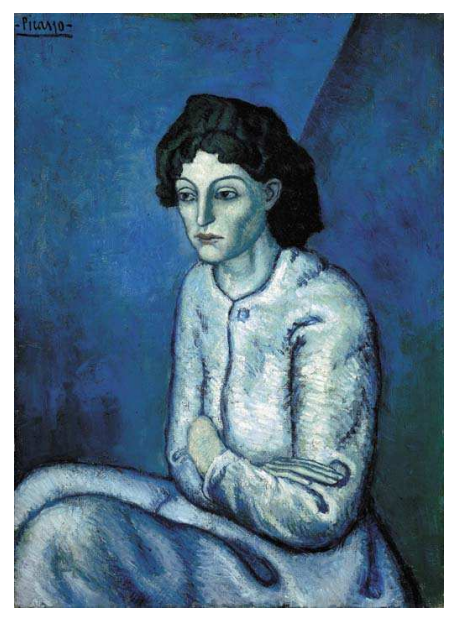

FEMME ASSISE EN

COSTUME ROUGE

SUR FOND BLEU, 1953

Christie's 8 May 2013

Price 8523750 USD

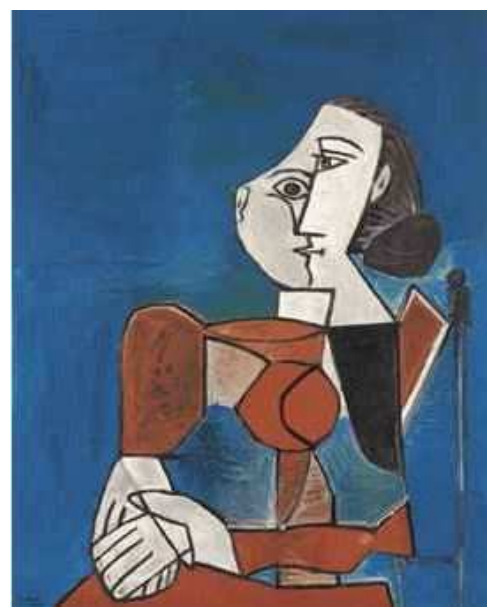

TETE DE FEMME (PORTRAIT DE

FRANCOISE), 1946

Sotheby's 2 May 2012

Price 6914500 USD

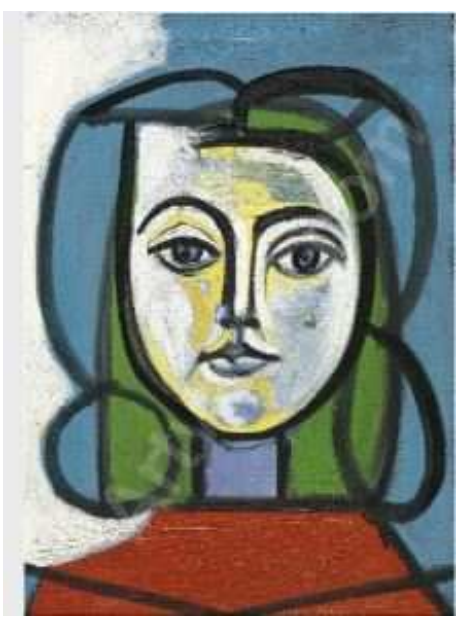

Figure 6: Example of paintings that belong to the orange cluster

FEMME AU

CHAPEAU VERT, 1947

Sotheby's 4 Nov 2009

Price 8146500 USD

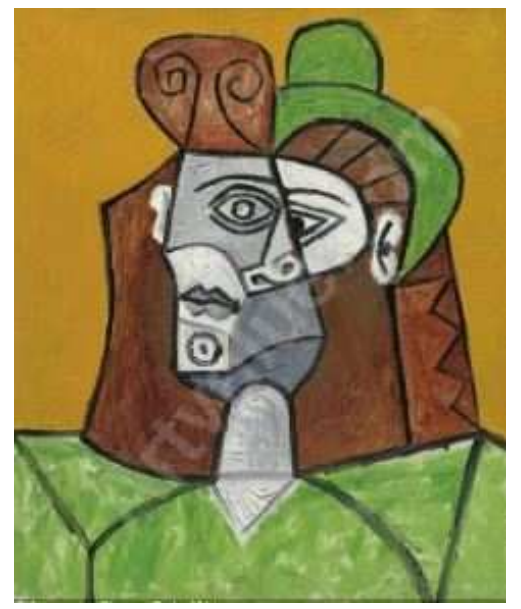

FEMME ASSISE DANS UN

FAUTEUIL, 1953

Sotheby's 7 May 2014

Price estimate 8000000 USD

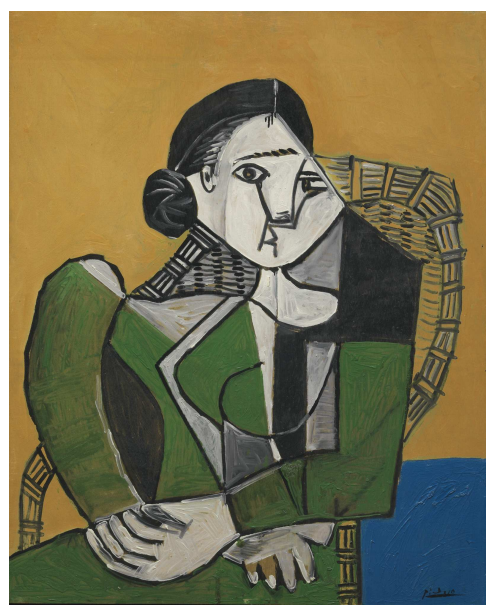

JEUNE FILLE AUX CHEVEUX NOIRS

(DORA MAAR), 1939

Sotheby's 8 May 2007

Price 8216000 USD

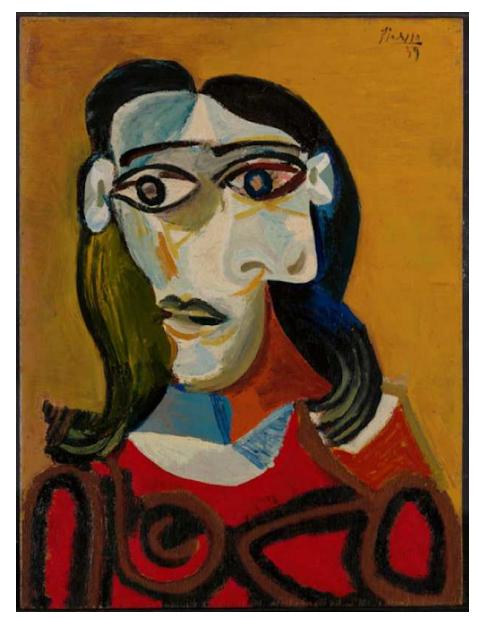


Figure 7: Fixed effects of Picasso's working periods (Table 1) and the number of artworks from each period in our dataset

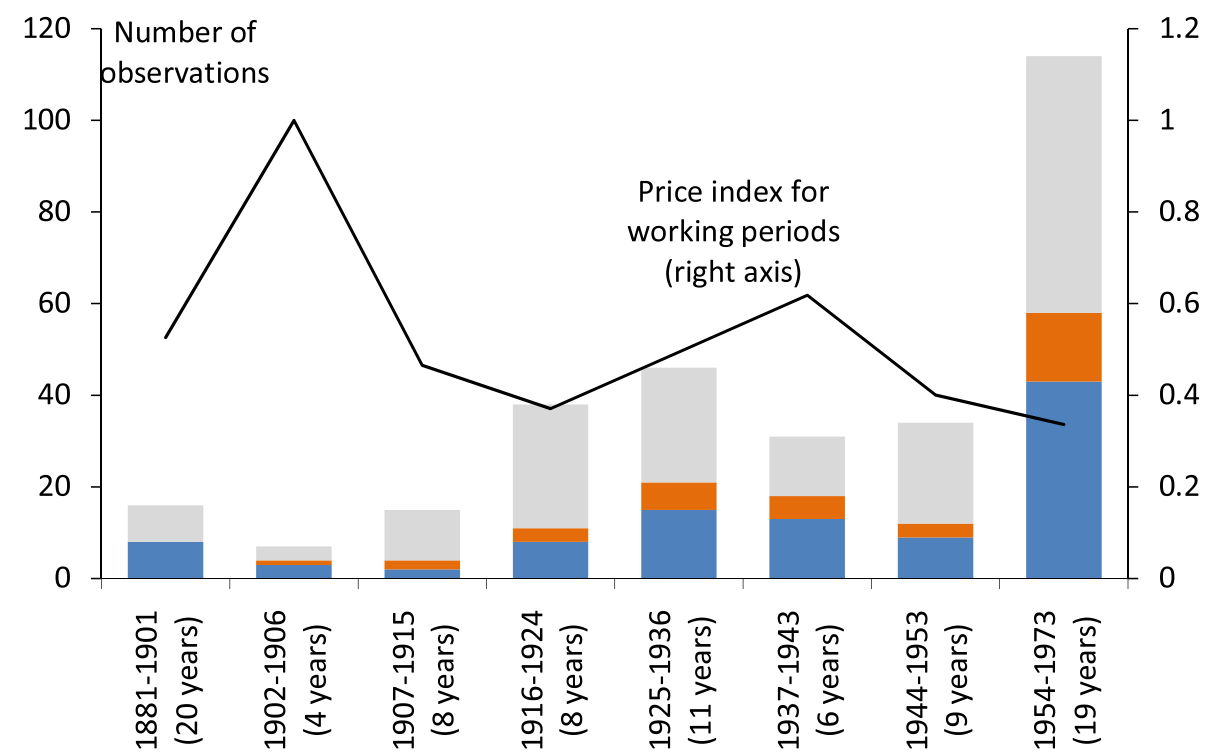

Note: The reference period, the Blue and Rose period (1902-1906) is set up to 1. Bars indicate the number of works belonging to a particular working period. The works that belong to the blue-teal cluster are in blue, the works that belong to the orange cluster are in orange, the rest of the works from a particular period that do not belong to neither of the two clusters are in gray

Figure 8: Price indexes of Picasso's paintings and paintings of Color Field Abstract Expressionists sold in New York

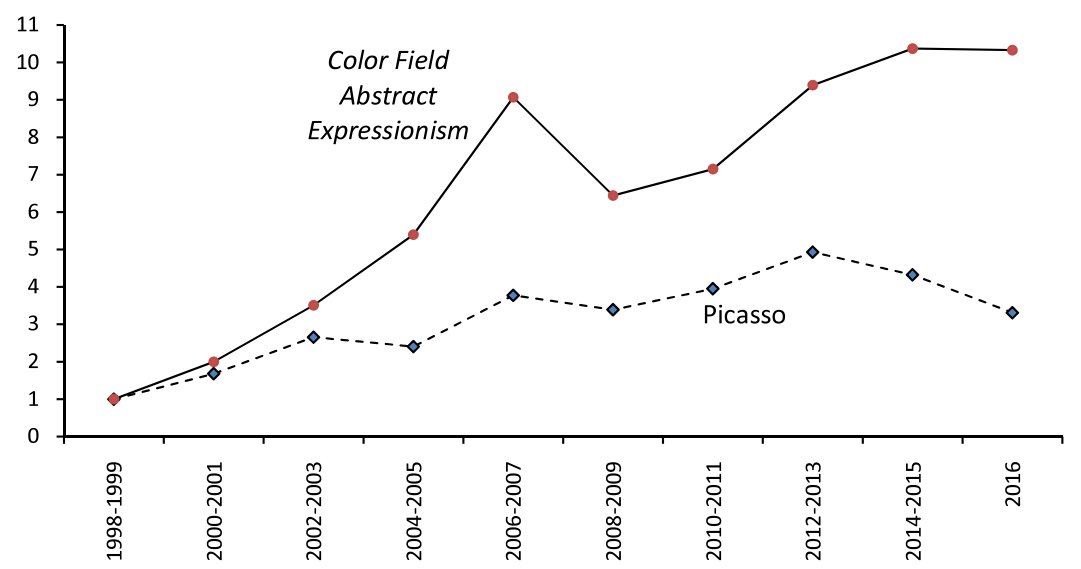

Note: Reference period is 1998-1999 and it is set up to 1. 